detail but untethered by the ropes of academic apparatus" so that "they let the balloon of ideas float free across the orthodox science/arts divide". During our repeated crossings of the Snow-line, we enjoy a stimulating and intermittently exhilarating ride, although it is never quite clear where the balloon is heading.

Graham Farmelo is at the Science Museum, Exhibition Road, London SW7 2DD, UK.

\section{Body work}

\section{David Goodstein and Judith Goodstein}

Twentieth Century Physics: Volumes I, II and III. Edited by Laurie M. Brown, Abraham Pais and Brian Pippard. Institute of Physics/American Institute of Physics: 1995. Pp. 2,059. £250, \$400 (3 vols).

THIs book is a monumental undertaking. In fact, speaking of undertaking, it is an obituary written before the body is cold. A few even think the heart may still be beating. Nevertheless, it will serve a number of important purposes.

With more than 2,000 pages in three volumes, Twentieth Century Physics is comprehensive. It opens with an essay by Brian Pippard on "Physics in 1900", followed by Abraham Pais on "Introducing Atoms and their Nuclei" and, a bit later in the volume, Laurie Brown on "Nuclear Forces, Mesons, and Isospin Symmetry". The third volume closes with philosophical essays on the history, substance and social structure of twentieth-century physics by Philip Anderson, Steven Weinberg and John Ziman. In between, the various fields of physics and closely related sciences (medical physics, geophysics) are covered by their practitioners. The level is uncompromisingly technical. This is not a reference for schoolchildren or journalists.

What is it then? According to the editors, they have created it because the history of physics is too important to be left to the historians. This, they imply, is history as it ought to be written, done by the pros, the participants who are qualified to decide what matters and what doesn't. In short, this is the peculiar view of history seen in a thousand physics textbooks, distilled to an undiluted essence. If nothing else, it shows us vividly how physicists wish to see their craft portrayed.

Physics, we learn, does not depend on the people who discovered it, or on the conditions in which they lived. Pais quotes a biographer of Rutherford: "People ask... what was the man like, did he really look like a farmer.... None of these things really matter." Physics, then, in a first approximation, is a body of knowledge about things, thoroughly drained of flesh and blood.

Ah, but that won't do of course. The physicists' egos won't permit it. Impersonal phenomena, such as Compton scattering or the Mössbauer effect, get named after real people. In these volumes, the technique for reintroducing life onto the barren planet of physics is some 63 biographical sketches, set off in boxes, scattered through the three volumes. In fact, this is one of the most important functions that the editors and their contributors have taken on. This is an anointing of the winners, and an omitting of the losers. It is, at the very least, an updating of the scoreboard in the great and noble competition of physics.

Of the 63 sketches, 61 are about white, European or American males (Ryogo Kubo and Hideki Yukawa are the exceptions). Incredibly, Robert Millikan is omitted, although his student Carl Anderson is included (can the positron really be more important than the electron?). Beyond this galaxy of superstars, every physicist who picks up this set of volumes will flip first to the name index to see if he's made it (they are nearly all he's). Brown, Pais and Pippard had better be prepared to take some heat.

It is hard to imagine a history of anything in the twentieth century that omits completely to mention that great cataclysmic event at the middle of the century, the Second World War. This is especially true of physics, where the war had immense effects, both positive and negative. Twentieth Century Physics tries hard to ignore it, and almost succeeds, but not quite. For example, of Max Planck, we are told that "he defended German science in the difficult times of the Third Reich", and we learn that Nernst's school, "sadly depleted by Nazi anti-Jewish measures, flourished in exile". Nevertheless, the Second World War doesn't make the subject index, and neither does Los Alamos.

All of the above is more or less made inevitable by the nature of the subject and the task that the editors and contributors set for themselves. Within the limits of that task, their accomplishment is impressive. As one might expect, the contributed articles are a bit uneven. Most read like physics review articles, typically found in the journal Reviews of Modern Physics. All are professional and authoritative, although a few tend to re-draw the map slightly to place the author closer to the centre. Dividing up the subject matter must have been difficult. For example, the subdiscipline that calls itself 'condensed matter physics' is represented by articles on crystallography by William Cochran, statistical mechanics (largely critical phenomena) by Cyril Domb, nonequilibrium statistical mechanics by Max Dresden, superfluids by A. J. Leggett, phonons and spin waves by R. A. Cowley and Pippard, magnetism by K. W. H. Stevens, electrons in solids by Pippard, materials by Robert Cahn and polymers and the like by P. G. de Gennes. Cross references are achieved by boxes in the margin saying "see also page $\mathrm{xxx}$ ".

Nobody is going to read through these three volumes from cover to cover. Not even we managed that, despite heroic efforts and gallons of black coffee. But many physicists will dip into them and read sections with real pleasure. The work will also provide source material to spruce up courses and seminars with a bit of historical introduction. All this is very much to the good. The only remaining question is will it serve the main purpose the editors had in mind?

It seems clear that the editors intend their volumes to survey the territory and lay out the road maps and instructions by means of which future historians of science will find their way around physics in the twentieth century. Given the generally abysmal state of the secondary historical literature in this field, they may well succeed, up to a point. These essays are not a bad way to get an initial overall orientation to what happened in a given area. But real historians will want much more than is available here. Physicists can and do speak with confidence and authority (some would say arrogance) about their discipline, and this series is a perfect example of that. Nevertheless, this much will remain true: historians always have the last word. When historians write the story of twentieth-century physics, they will put the flesh and blood back into it.

David Goodstein and Judith Goodstein are at the California Institute of Technology, Pasadena, California 91125, USA.

\section{New and notable}

Fire in the Mind: Science, Faith and the

Search for Order by George Johnson. Viking, £18. A New York Times science writer's overview of some of the emerging new ideas in physics and biology coming out of Los Alamos National Laboratories and the Santa Fe Institute in New Mexico.

\section{Charles Darwin's Letters: A Selection} 1825-1859 edited by Frederick

Burkhardt. Cambridge University Press, £45, \$54.95 (hbk), £15.95, \$19.95

(pbk). Letters taken from the monumental Cambridge edition of The Correspondence which reveal the human story behind the Origin of Species.

Dinosaur in a Haystack: Reflections in Natural History by Stephen Jay Gould. Harmony/Cape, \$25. The author's seventh collection of masterly musings on evolution and other natural phenomena, culled from his monthly column in Natural History magazine. 